\title{
O Cinema Escolar como Berço do Entretenimento
}

\author{
Fábio de Godoy Del Picchia Zanoni' \\ 'Universidade de Lisboa (ULISBOA), Lisboa - Portugal
}

RESUMO - O Cinema Escolar como Berço do Entretenimento. O artigo que ora se apresenta pretende trazer à baila o processo histórico de constituição de um modelo específico de endereçamento ao cinema. À contramão do que tendemos a supor à primeira vista, o presente artigo busca argumentar, sobretudo a partir das teorizações foucaultianas, como a emergência do cinema de entretenimento não se explica a contento tão somente pelos ditames e exigência de cunho econômico, pois foi indissociável da escolarização do cinema ocorrida nos muros da escola brasileira e portuguesa, ao menos desde meados da década de 1930.

Palavras-chave: Cinema. Escola. Genealogia. Foucault.

ABSTRACT - School Cinema as Birthplace of Entertainment. The article presented here intends to bring up the historical formation process of a specific model of addressing the movies. To the contrary to what we tend to assume at first glance, this paper seeks to argue, especially from Foucault's theories, as the emergence of entertainment cinema cannot be explained to the satisfaction solely by the dictates and demands of economic developments, because it was inseparable from schooling of cinema that occurred in the Brazilian and Portuguese school, at least since the mid-1930s.

Keywords: Cinema. School. Genealogy. Foucault.

Educação \& Realidade, Porto Alegre, v. 42, n. 2, p. 557-577, abr./jun. 2017. 557 http://dx.doi.org/10.1590/2175-623654581 


\title{
Introdução
}

\author{
A mudança do crer na autoridade para o \\ acreditar na própria convicção não muda o \\ conteúdo do discurso (Hegel, 1992, p. 67).
}

Na introdução do seu livro Princípios da Filosofia do Direito, Hegel lança a seguinte proposição: “o racional é real e o real é racional” (Hegel, 2009, p. 12). Foucault apropriar-se-á da identificação entre racionalidade e realidade, não para estabelecer meditações de cariz ontológico, mas para contornar a ideia de irracionalidade que tende a ser anexada à compreensão de certos acontecimentos históricos, e, assim, evidenciar como até mesmo os acontecimentos violentos - à semelhança dos suplícios analisados em Vigiar e Punir - são sustentados por racionalidades específicas, que visam a determinados objetivos políticos:

\begin{abstract}
Inexplicável, talvez, mas certamente não irregular nem selvagem. O suplício é uma técnica e não deve ser equiparada aos extremos de uma raiva sem lei. [...] a morte-suplício é a arte de reter a vida no sofrimento, subdividindo-a em 'mil mortes' e obtendo, antes de cessar a existência, the most exquisite agonies (Foucault, 1987, p. 31).
\end{abstract}

Do mesmo modo que Foucault, a fim de mapear o funcionamento do suplício, não se referencia aos descaminhos éticos dos reis ou dos carrascos, pretendemos argumentar como o prazer produzido no contato com o cinema foi também o resultado da internalização de certa racionalidade política. Seria possível, portanto, pensar o prazer fora do registro da irracionalidade e suas variantes (a espontaneidade, o instinto, etc.)?

Do ponto de vista das práticas históricas de constituição da experiência cinematográfica no Brasil e em Portugal, a instituição escolar não inaugurou o gesto de utilização do cinema. Inicialmente, as intervenções sobre os afazeres cinematográficos assumiram feições jurídicas e policiais. Além disso, elas não incidiram sobre o aluno, mas sobre os malefícios imputados ao ato de assistir ao cinema. Nos idos de 1910, a imprensa paulistana conclamava a polícia para reprimir os menores, menores que, em troca de acesso aos filmes, esfalfavam-se de trabalhar nas casas de diversões:

\begin{abstract}
Os garotos fugiam de casa, para desespero das mães, e se entregavam a pequenos serviços nos cinematógrafos: varrer e lavar o salão, entregar cartazes pelos arrabaldes mesmo distantes, distribuir programas nas ruas, de casa em casa, ajudar o operador, carregar tabuletas, carregar lanternas à noite juntos aos músicos, e tudo isto a troco de um prato de comida ou para ter o privilégio de assistir aos filmes (Araújo, 1981, p. 183).
\end{abstract}

Em relação aos processos de constituição da criança-espectador, não há motivo para titubear: não pululou, ali, reflexões acerca dos processos cognitivos envolvidos no ato de assistir ao cinema, pois o hábito 
cinematográfico não fazia parte do caldeirão da alta cultura. Quando muito, o cinema era visto como uma entre tantas experiências portadoras de riscos à criança e ao jovem. Contudo, e concomitantemente, esse cenário ganha novos contornos com o desembarque do cinema no ambiente da escola formal, especialmente a partir da década de 1930. Isso não implica que a escola tenha inventado o que entendemos por espectador de cinema. Nesse sentido, vale lembrar que o espectador de cinema só avolumará espessura quando inteligibilizado pelos ditos e escritos provenientes do advento do movimento cineclubista, emergente nos finais da década de 1940. No entanto, é inegável que foi no interior dos muros da escola que a recepção aos filmes, apoiada na figura do aluno-espectador, passou a portar dimensões cognitivas.

\section{Qual Escola?}

O cinema é parte fundamental dos projetos da chamada Escola Nova, uma forma de escolarização em funcionamento tanto em Portugal como no Brasil, mais precisamente um movimento de reorganização das orientações pedagógicas mestras, orientações que, a partir de 1920 e 1930, içavam como bandeira a expansão do jogo ensino/aprendizagem para além do formalismo do ensino tradicional. Ensinar, sem educar, não era mais suficiente (Nunes, 1943), pois o fulcral radicava em uma educação integral. Em 1927, a reforma de ensino no Brasil adquiria existência tendo como lastro teórico a premissa de o gesto educativo não jazer “[...] em produto algum de perícia humana” (Lourenço Filho, 1956, p. 56), mas unicamente no contato direto com as vivências imediatas. A partir de então, a narrativa professoral, ao se lançar entre o aluno e a apreensão imediata da vida, ocupava o lugar de impasse ao aprimoramento do ensino. Donde a pergunta: como se tornou historicamente viável que o cinema, um dos tantos instrumentos sociais da mediação, fosse mobilizado como dispositivo capaz de tornar o ensino mais atrativo? Antes de mais nada, cumpre vincar os pressupostos da Escola Nova.

Desde 1930, o Brasil experimentava um processo de transição entre duas visões pedagógicas (Arquivo..., 1935). O ensino escolar tradicional, de um lado. De outro lado, a vertente escolanovista. Pouco a pouco, o prato da balança vinha se mostrando favorável aos preceitos dos escolanovistas. Como já dito em outra ocasião: "O ensino escolar passou a ser, então, denunciado ora como excessivo, devido a fartura de disciplinas, livros e noções a serem empacotadas na memória, ora como deficiente, em virtude da falta de contato com as coisas" (Zanoni, 2015, p. 93).

A desconfiança em relação ao apego aos livros não ter redundado no enfraquecimento do gesto educativo é, certamente, o aspecto mais sobressalente. $\mathrm{O}$ perigo alardeado pelos pedagogos acerca dos malefícios do ensino até então adotado pelas escolas, perigo plasmado na dissociação escolar entre educação e instrução, gerava mais robustez para o projeto de uma educação integral. Quanto mais o denuncismo 
O Cinema Escolar como Berço do Entretenimento

à cultura livresca ganhava terreno, mais a escola bania de dentro de si qualquer forma de vazio educativo:

Cuidava-se [...] que só a instrução era necessária; e, para que assim fôsse, não se permitiam as crianças mais do que uns escassos momentos de recreio livre. $\mathrm{O}$ resto era estudo. Não se julgava necessário educar; bastava instruir (Nunes, 1943, p. 10).

Os benefícios da educação alemã nazista, imensamente centrais para a reconfiguração das propostas educacionais brasileiras imaginadas por Capanema, propostas tão bem descritas por autores como Ana Maria Dietrich (Dietrich, 2010), René Gertz (Gertz, 2013) e Ediógenes Aragão Santos (Santos, 2002), tinham que ver com o fato de o nacional-socialismo pleitear o indivíduo como um todo, uma meta, aliás, inatingível pela simples absorção dos conteúdos dos livros, embora perfeitamente exequível pela incitação da vontade, haja vista que somente a dimensão volitiva agarraria o ser do homem como um todo. Para o Ministério da Educação do Brasil varguista:

A educação do homem enquanto ser e a educação do seu comportamento, são duas finalidades psicológicas inseparavelmente unidas. Se nos preocupamos simplesmente com o comportamento, isto é, com as exterioridades [...] perdemos o contacto com a realidade substancial que perdura e que imprime o seu cunho inapagável em toda espécie de comportamentos possíveis (Arquivo..., 1938, p. $5)$.

Quem governasse a vontade, governaria a conduta, eis o ponto chave. As mesmas personalidades de destaque dos ambientes educativos formais que militavam pela concretização de uma educação integral também alimentavam a certeza a respeito da ilegitimidade de imposições autoritárias para a performação de efeitos de longa duração na alma do alunado, sublinhando, dessa feita, a inutilidade dos gestos educativos que estimulassem apenas a criação de um modo de ser do alunado que o tornasse dependente de uma figura exterior permanentemente ocupada com o papel de vigia. Daí o apelo para que as escolas substituíssem o comando advindo de uma figura exterior, usualmente individualizado na figura do professor ou do bedel, pelo fomento de um ambiente ordenador, onde qualquer sujeito em processo de aprendizagem pudesse incorporar naturalmente as injunções da instituição escolar.

Do ângulo dos teóricos da Escola Nova, o ideal do homem livre tinha seus dias contados, pois o que se buscava era o desabrochar do homem natural, como se pudesse haver uma espécie de total coincidência entre os quereres individuais e as expectativas institucionais. Não fosse assim, a liberdade tomaria a forma do liberticídio, voltando-se contra si. Se era certo que a liberdade do homem estava na base da autodestruição de si, as autoridades tinham a inelutável obrigação de delinear as margens dentro dos quais fluiriam as aptidões individuais, obrigação

560 Educação \& Realidade, Porto Alegre, v. 42, n. 2, p. 557-577, abr./jun. 2017. 
ainda mais premente diante da incontinência da juventude, essa fase na qual o sujeito se acha predisposto a "ser e agir" (Serrano; Venâncio Filho, 1931, p. 19). A disparidade cognitiva e ética entre o homem natural e o livre materializar-se-ia em dois tipos distintos de governo de si, a saber, o autogoverno e a autonomia:

O termo self-government, usado tantas vêzes em substituição a autonomia, é ainda mais expressivo. Não se governa a si mesmo sem se deixar ir ao sabor da fantasia ou do capricho do momento. O self-government implica o domínio próprio, isto é, a dominação das tendência instintivas ou irracionais (Serrano; Venâncio Filho, 1931, p. 122).

Para que os princípios de reforma da escola fossem respeitados, os adeptos da Escola Nova tinham necessariamente que abrir mão da ação proibitiva abertamente limitadora da liberdade. Por isso, a centralidade de promover junto aos alunos o contato com as próprias coisas e os momentos de lazer, na medida em que um e outro tinham o condão de efetivar a restrição da liberdade sem nenhum apelo à autoridade direta do professor. Pois, claro, as propriedades inerentes à coisa, bem como as regras imanentes aos jogos, estabeleciam aos alunos limites que seriam experimentados como naturais. Novamente, vale recuperar o que foi dito sobre o mesmo tópico em outra ocasião:

\begin{abstract}
No contato com as coisas e nas brincadeiras, o que estava em questão não era a descoberta de verdades insuspeitas, mas a operacionalização de novos métodos de ensino, cuja distância em relação ao fantasma da chancela da tradição no processo de aquisição e valoração da verdade ministrada pela escola não implicasse abrir mão da recognição como modelo central de acesso ao verdadeiro (Zanoni, 2015, p. 96).
\end{abstract}

O que estava em linha de frente era a aposta de a verdade poder esbanjar mais força de pregnância quando reconstituída pelo próprio indivíduo. Isso significa, precisamente: a diminuição do caráter impositivo do comportamento professoral não expulsou da escola formal o protocolo de definição prévia da verdade por parte das autoridades, muito embora tenha realocado os meios de transmissão da verdade antes confiados às bibliotecas e à narrativa professoral - em direção às brincadeiras e às coisas, subtraindo a violência expressa das autoridades em benefício da evidência das coisas e da leveza das brincadeiras, 0 que terminava por solidificar a institucionalização de práticas de objetivação da verdade que dificilmente consentiriam qualquer alternativa - apesar da sombra da violência direta e aberta ter deixado de pairar no ar. As reflexões contida no livro de Paul Foulquié escancaravam as estratégias de cooptação da adesão voluntária dos alunos aos comandos escolares previamente fixados:

A criança não é, pois, deixada a si mesma senão aparentemente. Desfruta, sem dúvida, grande liberdade e não tem imposta qualquer ocupação que não a interesse. Mas 
O Cinema Escolar como Berço do Entretenimento

o material que lhe é proporcionado orienta o seu interesse no sentido havido por melhor para sua formação intelectual. Os exercícios educativos a que se entrega espontaneamente são muito diferentes dos da escola tradicional, mas, como nesta, se sucedem numa ordem metódica e previamente estabelecida (Foulquié, 1952, p. 24).

Portanto, à contramão dos dizeres hegelianas, a mudança do crer na autoridade para o acreditar na própria convicção reorientava a definição da origem dos enunciados verdadeiros que seriam anexados à identidade dos alunos. Elegendo como plataforma as demandas supostamente fabricadas no interior das fronteiras da individualidade dos alunos, tanto os jogos quanto a descoberta das coisas proporcionavam ao ambiente escolar os recursos para a encenação de outro modo de teatralização da verdade, só que agora sujeito apenas à espontaneidade da horizontalidade entre aluno e aluno, bem como entre aluno e coisa, guarnecendo as autoridades escolares com as ferramentas de ressignificação dos dispositivos de regulação da conduta do aluno, que passavam a assumir não apenas um aspecto tolerável, mas, acima de tudo, desejável. Os projetos de montagem do jardim da infância escolar mostravam claramente os objetivos da inclusão do aluno em experiências lúdicas, ao explicitar a destreza com que a incitação à participação dos alunos nas brincadeiras escolares impactava a conversão das regras impostas por figuras externas de autoridade em demandas individuais nascidas no contato direto com os jogos:

[...] no jardim, mesmo as atividades dirigidas são apresentadas como jogos e, por isso, se tornam atraentes. As atividades de livre escolha têm seus limites marcados pelas exigências da vida em comum. Liberdade, nessas condições, é autoeducação. A criança descobre logo que, para ser bem aceita, precisa ser amável e cordata, saber esperar a sua vez e controlar-se quando contrariada; ceder quando necessário e colaborar sempre que solicitada; A rebeldia traz uma segregação temporária da coletividade, não como punição, mas para favorecer a reflexão e a calma. Logo que volte a possibilidade de comportamento adequado é facultado o regresso ao grupo, sem que tenha havido humilhação nem censura. A autoeducação dá o gosto pelo esforço (Schmidt, 1958, p. 203).

Com o fim da violência física por parte do professorado, os alunos conquistaram - em tese - o direito de não serem objetos dos furores dos mais velhos. Todavia, o medo de não pertencimento ao grupo, medo capitaneado pela impessoalidade das regras do jogo, tornava-se normal, e a rotinização da norma tanto mais incontornável quanto mais vigorosa a condensação entre as expectativas das autoridades e os efeitos punitivos decorrentes da imanência das regras de cada um dos jogos. O nosso desejo por inserir os mais novos em jogos de toda sorte deixa de lado que tais atividades jamais foram fabuladas como uma suspensão provisória do poder normativo das autoridades escolares, muito menos como uma brecha para a criação de novas relações entre alunos e alunos ou 
entre alunos e professores, na medida em que o motor da maquinaria lúdica foi sempre acionado em decorrência da crença de que ela teria o condão de intensificar os mecanismos punitivos entre os pares:

Os jogos são uma condição para a disciplina dos colegiais. Neles há regras estabelecidas e aceitas pelo grupo de brinquedos e que são respeitadas como invioláveis. Para tomar parte nos brinquedos é preciso saber respeitar as regras do jogo. Isso disciplina o indivíduo, dá-lhe hábitos de governar-se a si mesmo (Penteado Junior, 1949, p. 171).

Essa sanha pelo incremento de formas de incitamento da autopunição talvez faça com que soe menos descabida a afirmação de as práticas ligadas ao lazer terem sido elaboradas apenas com razões que a própria razão deveria desconhecer. Com isso, não se quer dizer que o caráter inconsciente da adesão dos alunos às regras escolares esteja escondido no subterrâneo das mentalidades individuais, cuja revelação dar-se-ia por meio de movimentos de introspecção. Muito ao contrário. Resultado dos programas de socialização da Escola Nova, a formação do inconsciente advinha do escondimento dos princípios de regulação da conduta dos alunos, visto que tais princípios não deveriam pulular entre os holofotes da consciência. Do contrário, a eficácia ético-política das atividades tributárias da livre adesão dos alunos seria seriamente fragilizada. Por essas razões, a Escola Nova nunca cessou de embater-se em favor da orientação dos alunos por intermédio da definição de uma diretriz “[...] firme, segura, invisível embora” (Serrano; Venâncio Filho, 1931, p. 48). Em 1936, um deputado português, ao tecer seu elogio à força educativa do cinema, precisava os comandos silenciosos que estruturavam as rotinas lúdicas:

Educar é fazer passar o consciente para o inconsciente. Por outras palavras, educar é criar artificialmente hábitos. Mais rigorosamente: bons hábitos (Assembléia da República, 1936, p. 458).

Passar do consciente ao inconsciente, naturalizando um conjunto específico de hábitos, eis a melhor descrição das experiências lúdicas em que o cinema escolar foi inscrito. Isso implica, entre outras coisas: no âmbito da consciência somente a alegria deveria despontar, ao passo que as regras de socialização transportadas pela experiência lúdica deveriam estar silenciadas pelos ângulos cegos que perfazem a consciência.

A expansão dos momentos de lazer redundou em variadas formas de reorganização temporal e espacial das rotinas escolares, rotinas que passaram a mobilizar idas aos bosques internos, às quadras de esporte, aos brinquedos, à prática musical, à feitura de desenhos, ao visionamento de filmes, entre outras tantas tecnologias lúdicas de socialização. Sem demora, a instituição escolar inventou uma complexa "maquinaria da alegria" (Serrano; Venâncio Filho, 1931, p. 17), até então alheia aos hábitos escolares. Rapidamente, essas atividades passaram a serem paisagens normalizadas. Mas também normalizadoras, na medi- 
O Cinema Escolar como Berço do Entretenimento

da em que atuavam como prolongamento disciplinar da escola. $\mathrm{Ou}$, dito de modo simples, ainda que à primeira vista não tivessem parentescos com os instrumentos de disciplina em circulação nas escolas, cabiam às atividades lúdicas regularem a autonomia dos alunos, produzindo a adaptação deles tanto na escola quanto na família.

Vale lembrar que a relação entre o ensino e as experiências lúdicas não se obrava no regime temporal da sucessão, como se as brincadeiras tivessem início após o término da educação. A brincadeira não se imiscuía nos momentos de interrupção das atividades escolares. O sucesso da experiência lúdica dependia da osmose entre brincadeira e educação. Segundo os peritos da educação no Brasil, "atrair e educar" (Arquivo..., 1940 , p. 11) não era uma tarefa que poderia ser levada a cabo por leigos, principalmente em virtude do fato de que essas duas ações tinham que concomitar, fundindo o "[...] trabalho normal da escola e a recreação" (Serrano; Venâncio Filho, 1931, p. 24), o único modo de operacionalizar a máxima de o ser-que-brinca ser também o ser-que-aprende (Schmidt, 1958). E, apesar de tudo isso, é inegável que há imensa resistência para imaginarmos as alianças entre o prazer e certos projetos de governo cuja ambição consiste em alvejar objetivos políticos específicos. Se estivermos acompanhando que a produção do prazer foi uma exigência pedagógica complexa, isso se devia ao fato de haver uma enorme dificuldade em definir com exatidão o que poderia "agradar a uma criança" (Serrano; Venâncio Filho, 1931, p. 20). De todo modo, onde emergia o termo brinquedos, ou diversão, ou, ainda, alegria, prontamente surgia o alerta para que não houvesse divisão entre “[...] brinquedo-diversão e brinquedo-educativo” (Serrano; Venâncio Filho, 1931, p. 24):

\begin{abstract}
1- Que hábitos sadios podem ser desenvolvidos e estimulados com o uso de tal brinquedo?

2 - Que maus hábitos podem ser estabelecidos?

3 - Em cada idade, quais os interesses dominantes que precisam ser desenvolvidos e que brinquedos estimularão estes interesses para a formação de bons hábitos?

4 - Nestes interesses, quais os de maior importância e quais os que podem ser adiados até se tornarem mais fortes? (Serrano; Venâncio Filho, 1931, p. 21).
\end{abstract}

Apesar dos benefícios políticos da introdução das experiências lúdicas nas escolas, a imersão dos alunos nas brincadeiras trazia sempre o risco de que eles contraíssem maus hábitos. Daí a partilha entre estes e bons hábitos. Daí também a separação entre brinquedos proibidos e permitidos. Claro, os proibidos eram todos aqueles que provocavam conflitos físicos. Mas também os jogos de azar, pois neles não havia nada que não se tornasse um pretexto para as roletas. Enfim, se não submetidas aos programas de formação de bons hábitos, as brincadeiras podiam ser condenadas como alheamento do indivíduo diante da realidade, situação semelhante ao consumo de drogas:

[...] outros preferem o álcool ou os entorpecentes. Mas o jogo, mais do que estes, conduz os viciados a um estado de 
alheamento da realidade ambiente, exceto o próprio jogo (Schmidt, 1958, p. 72).

Embora nos cause alguma estranheza, os "brinquedos moralizadores" (Serrano; Venâncio Filho, 1931, p. 19) representavam um perigo ainda mais grave, visto que tais brinquedos carregavam no seu bojo a tendência de levar a criança, devido ao enfado de seus procedimentos propositivos, para bem longe dos jogos.

Se isso ocorresse, não apenas a participação voluntária do aluno desapareceria, mas também viria à tona o fato de a ação lúdica ser o resultado da confecção de regras de socialização da conduta dos alunos. Nenhum deles, nem os hábitos bons nem os ruins, lançavam o aluno rumo ao exterior do espaço da brincadeira. Isto é, somente o brinquedo aborrecedor fazia do aluno o receptáculo involuntário de princípios heterônimos de socialização, minando a eficácia do princípio de socialização em causa. Portanto, a experiência lúdica não podia acomodar, sob hipótese nenhuma, a desestruturação dos meios de acobertamento das regras a serem internalizadas pelo aluno escafandrado na brincadeira. Se a agressividade era um mal eventualmente produzido pela brincadeira, ela era apenas um mal menor. Sem dúvida nenhuma, a sensação de aborrecimento no momento da brincadeira constituía a temida flecha dirigida ao calcanhar da experiência lúdica.

\section{A Escolarização do Cinema}

Se estamos à volta com o tema do brinquedo aborrecedor, é precisamente pelo fato de o cinema ter sido encarado como a resposta mais adequada às suas ameaças. A assimilação escolar do cinema como meio de catapultar o aproveitamento dos alunos foi proporcional à verificação da ineficácia da captura da vontade dos alunos por meio de brinquedos e brincadeiras existentes no quadro da instituição escolar. Com o cinema, a escola almejava ampliar o desejo dos alunos pelas atividades lúdicas, de modo que a internalização inconsciente de regras de socialização ocorresse ainda mais desimpedidamente. Ao sair em defesa da validade de certo cinema para a educação, José Maria Gaspar, no seu livro O Cinema e a Escola, indicava de que modo o cinema poderia animar o aluno em direção ao bem, contanto que o recreasse e o divertisse (Gaspar, 1948). Nos idos de 1939, fazendo frente aos que associavam o cinema aos descaminhos da instrução, um deputado do parlamento português dizia em alto e bom som:

Nenhumas considerações impedem que [.] se lhes proporcione alguns momentos de sã alegria que para elas representa a assistência a um divertimento, à projeção de um filme [...] se os filmes forem cuidadosamente adaptados à mentalidade infantil, podem mesmo nessa idade servir de instrumento de educação [...] ministrando-lhes pequeninos exemplos de ordem, que bem poderão completar os objetivos da educação doméstica (Assembléia da República, 1939, p. 14). 
Os enunciados favoráveis à inclusão do cinema na escola tinham por objetivo provar que a disciplina nasceria da alegria. (Nunes, 1943), e isso porque o cinema lançava mal de "mil truques" (Didonet, 1957, p. 5), hiperbolizando o envolvimento do aluno-espectador, sobretudo depois da invenção do cinema sonoro, visto que a entrada em cena de mais um componente de realidade aumentava significativamente a capacidade de sedução das imagens em movimento. Refém voluntário da força de sugestão do cinema, o aluno-espectador era então mais facilmente guiado. Quer o cinema visto dentro da escola, quer o cinema extracurricular, ambos inscrever-se-ão nessa vinculação entre educação e lazer:

A recreação, quando é racional, é fator educativo [...]. Recreação é relaxamento do organismo e da mente [...]. É atividade livremente escolhida e exercida nas horas de lazer, ativa ou passiva, individual ou em grupo, organizada ou espontânea [...]. A característica da recreação é [...]. ser atividade 'de luxo', isto é, desinteressada, que transforma e corrige a realidade (Schmidt, 1958, p. 43).

$\mathrm{O}$ uso do cinema a que venho me remetendo enraizou-se nos territórios educativos brasileiros a partir da promulgação da reforma Francisco Campos, de 1931. Nela, a iconografia - sob a alegação de as crianças e os adolescentes sentirem uma natural atração pelas imagens, via-se recomendada como auxílio ao ensino de história. Se as imagens em geral deviam ser empregadas, não faltava senão um passo para o cabimento das imagens em movimento. Entre tantos questionamentos, uma pergunta avultava. Sendo certo que a indústria inventara uma "animação nova” (Schmidt, 1958, p. 24), se essa animação não se cansava de recrutar a juventude, por que não a adotar como modelo de internalização de regras? Em todo caso, o que importa sublinhar é que a imagem, em geral, e a imagem em movimento, em particular, tornavam-se procedimentos fundamentais para a fixação do conteúdo curricular. Mas, ainda mais importante, importa reter que os sucessivos esforços para a incorporação do cinema na escola não se fizeram em vista das suas qualidades estéticas, pois o que se achava em jogo era o recurso audiovisual como meio de consecução de fins de ordem educativa.

Que o cinema tivesse servido aos intentos da pedagogia nazista não era de pouca monta. Durante largo período de tempo, as políticas educativas alemãs funcionaram como o norte das pedagogias brasileiras e portuguesas. Por isso, os pedagogos de Portugal, especialmente os adeptos da inclusão do cinema na escola, voltavam seus olhos para o tipo de aproveitamento do cinema que vinha ocorrendo em terras alemãs, onde o material cinematográfico circulava abundantemente pelas escolas. Ora, se Portugal fosse capaz de glosar as práticas da pedagogia alemã junto ao cinema, em pouco tempo não haveria disciplina que não fosse “[...] ilustrada pelo filme pedagógico" (Liga..., 1934, p. 7). O conceito de ilustração era muito mais do que uma maneira vaga de intuir o papel pedagógico das imagens em movimento. Isto é, a pertinência do cinema na escola não se decidiria apenas em virtude do cinema pertencer ao baú de ferramentas que compunham as experiências lúdicas. 
Paralelamente, o cabimento do cinema dependia da validação do dispositivo da ilustração, na medida em que permitiria ao cinema, mesmo sendo este um instrumento de mediação social, distanciar-se do professor tagarela:

O cinema fala por meio das imagens, que se transformam em ideias e juízos. O cinema impõe ideias com mais força do que o livro, porque este fala sobre as coisas, enquanto o cinema as mostra diretamente (Didonet, 1957, p. 4).

Devidamente localizada, a ilustração foi o nome dado à capacidade do cinema para transformar as imagens em movimento em realidades semipresentes. Tudo se passa como se, na escala crescente composta pelo falar, pelo ilustrar e pelo oferecer as próprias coisas ao campo de observação dos alunos, o cinema estivesse no degrau acima do professor tagarela: o cinema era, pois, simultaneamente um não discurso e uma quase coisa, isto é, um ser intermediário dotado de elevado poder epistemológico.

Pelo aumento do número de meios de objetivação dos conteúdos ministrados e dos sentidos mobilizados na assimilação das informações, o cinema deveria ser situado a meio caminho entre as próprias coisas e a abstração da ideia vocalizada. $\mathrm{E}$, assim, destergiversado pelo cinema, a dinâmica de ensino/aprendizagem escolar, outrora refém da falação do professor, ganhava nova feição, visto que os filmes ajudariam na remoção de certas dificuldades do trabalho escolar, sobretudo simplificando pela demonstração explicações longas e supérfluas (Zanoni, 2015, p. 107).

Na comparação com o poder de ilustração da imagem cinematográfica, o professor tagarela perdia a guerra, e essa derrota acrescia pontos importantes para o cinema escolar, já que o acervo fílmico das escolas deixaria de ser tão somente um meio de governo inconsciente dos alunos, tornando-se, em igual medida, um expediente para o desenvolvimento dos conhecimentos. Além disso, o cinema era infinitamente econômico, sobretudo em relação às visitas e às excursões para fora da escola, conhecidas por encetar "dificuldades de toda ordem" (Didonet, 1957, p. 116). Uma coisa é certa: sem a noção de ilustração, o cinema não teria abandonado a posição de entrave para as políticas pedagógicas que se orientavam pela exclusão das modalidades de ensino não lastreadas na observação e no contato direto com as coisas.

Como não podia deixar de ser, não faltaram críticos que se encaminhassem no sentido de alegar que o cinema descumpria esse duplo requisito. Fechado na recepção de imagens, o ensino via cinema passava ao largo da cooperação de todos os sentidos. Ao privilegiar a retina, a recepção fílmica desconsiderava o olfato e o tato. Confrontado com os ditos de Freinet, para quem o ato de aprender junto às próprias coisas era um dever pedagógico inalienável (Foulquié, 1952), o cinema perdia seu direito de cidadania nas escolas, a menos que fosse capaz de matizar as desqualificações que o criticavam por depender da media- 
ção de terceiros. Eis o problema: como o cinema seria um auxílio para a instrução se a observação direta era a principal etapa na elaboração dos conhecimentos e se o conhecimento propriamente dito era aquele que havia passado pelos sentidos? Como assistir aos filmes na escola se: "Toda a observação directa por meio dos sentidos é de muito mais alto valor do que a observação indireta por meios artificiais, quadros, modelos, filmes" (Liga..., 1934, p. 30).

Mesmo sendo verdade que não foram poucas as autoridades que se punham em um estado de indiferença total diante das lufadas argumentativas pró-cinema, especialmente no que dizia respeito ao lugar intermediário deste na produção do conhecimento, fazia-se por demais evidente que o cinema não atraía tantos senões quando ele apenas subsidiasse o enraizamento dos conhecimentos recolhidos no contato direto com as coisas, servindo de reforço aos saberes já circulados nos sacrossantos canais dos sentidos (ou, como veremos, aos saberes que não poderiam ser formados pelo contato direto). No fundo, não seria essa a melhor saída para reivindicar para o cinema um lugar no ensino? (Boletim..., 1955).

Mas mais: se os pedagogos tradicionais não se deixavam convencer a respeito dos benefícios epistemológicos contidos no uso do cinema em sala de aula como intermediário na produção do conhecimento, ninguém deixaria de inobservar que o cinema se punha, em compensação, como o meio ideal para que os alunos pudessem observar as realidades que não fossem imediata e diretamente acessíveis. Entusiasta do cinema na escola, Getúlio Vargas chamava a atenção para o poder do cinema em presentificar - de maneira veloz - os acontecimentos históricos, acontecimentos que, por definição, não se apresentam ao campo dos sentidos:

A técnica do cinema corresponde aos imperativos da vida contemporânea. Ao revés das gerações de ontem, obrigadas a consumir largo tempo no exame demorado e minucioso dos textos, as de hoje e, principalmente, as de amanhã, entrarão em contacto com os acontecimentos da História (Vargas, 1934, p. 1).

O conceito de ilustração acabou por não se avultar, no entanto, como o argumento mais poderoso para conferir ao cinema um lugar na escola. É certo que o cinema pode calar muito de seus detratores ao disponibilizar-se como complemento didático. Mas a palavra do professor e as imagens impressas nos livros já cumpriam a missão de reiterar a assimilação de realidades absorvidas pelos sentidos. Desse modo, o argumento que insistia na validade do cinema escolar em virtude de sua capacidade para transpor certas realidades para o interior da sala de aula era insuficiente, já que a vocalização do professor e a leitura de livros tinham precisamente o papel de enviar os alunos para as zonas especiais e temporais que exorbitassem à jurisdição dos sentidos dos alunos. Donde a relevância de o cinema ser, antes de mais nada, uma imagem em movimento. Só assim o cinema teria condições de esbanjar uma propriedade - o movimento - que o avantajasse perante as formas 
tradicionais de reforço do conhecimento adquirido junto ao real. Portanto, o uso do cinema estaria condicionado pelas situações "[...] em que o movimento seja fator essencial" (Serrano; Venâncio Filho, 1931, p. 48): o curso das águas, diziam Serrano e Venâncio.

Mas não só. Caberia ao cinema captar as situações nas quais a observação direta implicasse um risco à integridade física dos alunos: vulcões e distúrbios sociais em erupção. Assim, e só assim, o cinema neutralizaria o valor de verdade das atribuições negativas atribuídas à si:

\begin{abstract}
Na técnica moderna de educação, em que a criança deve ser posta em contato com a realidade mesma, toda vez que a natureza não puder estar diante dela, recorre-se aos meios artificiais, para trazê-la ao aluno, desde que ele não pode ir até lá (Serrano; Venâncio Filho, 1931, p. 60).
\end{abstract}

As autoridades sequiosas pela inserção dos filmes na escola buscaram um espaço para o cinema entre as ferramentas pedagógicas tradicionais, muito embora não deixassem de vincar os riscos de que alguns abusassem do emprego do cinema. Como os demais recursos didáticos, o cinema podia e deveria ter seu lugar, seu momento, em suma, sua didática. Dito isso, cabe a pergunta: se o cinema era portador de tantos dotes epistemológicos (ilustração e reforço da realidade), bem como de dotes disciplinadores (internalização inconsciente de regras de conduta), como ele não teria tido cabimento entre os muros da escola? Ora, malgrado o relativo sucesso do cinema como expediente pedagógico, os argumentos que propugnavam a retirada do cinema da escola levariam a melhor.

\title{
Instrução ou Educação?
}

Sim, o cinema não foi acolhido de braços abertos pela instituição escolar, e isso porque o cinema, apesar de um ou dois benefícios educativos, causaria, ao cabo e ao fim, enormes prejuízos à instrução, visto que o tipo de internalização dos saberes proporcionado pelo cinema atravancava o desenvolvimento cognitivo dos alunos. Sem nenhuma sombra de exceção, o cinema era acusado de produzir um modo de aprendizado baseado na facilidade da absorção dos conteúdos ministrados, facilidade que desembocava ora na própria natureza da imagem, ora nas faculdades humanas, ora na relação entre uma e outra. Tal como algumas faculdades cognitivas estavam de raiz destinadas às verdades inteligíveis, outras gozavam de maior inclinação para a captação do universo sensível.

Nunca o teatro de ação conseguirá sintetizar tanto movimento como a passagem duma fita de animatógrafo. Porque o ouvido tem menos agudeza sensível que o olhar. E a sugestão no teatro será mais lenta (Neves, 1946, p. 10).

Por vezes, a facilidade na recepção das imagens em movimento não se fazia pela remissão aos sentidos, sendo a natureza da imagem a 
O Cinema Escolar como Berço do Entretenimento

própria origem dessa indevida facilidade de assimilação. Grosso modo, a materialidade do cinema contrastaria com a da literatura e a do teatro. Elegendo aquela como termo de comparação, concluía-se que o cinema, no lugar de fazer pensar "[...] por meio de nomes que são etiquetas" (Neves, 1946, p. 29), ofertava aos alunos a impressão de estarem em contato com as próprias coisas, ou, o que vinha a dar no mesmo, enquanto o cinema exibia, mostrava, presentificava, a literatura apenas indicava (Boletim..., 1953), exigindo uma maior participação do intelecto do aluno. Em linhas gerais, poderíamos asseverar que:

A degradação do estatuto gnosiológico do cinema adviria, pois, do fato de a imagem no cinema ser o avesso do índice, de ela não se comportar como o signo de algo outro, à moda da etiqueta, deixando de servir como trampolim para as próprias coisas. Tudo se passa como se o aparato cinematográfico, na boca dos adversários da escolarização do cinema, não pudesse ser aceito exatamente por cumprir em demasia o que os defensores do cinema escolar se esforçavam por provar que o cinema poderia cumprir em grau incompleto: a presentificação da coisa exibida pela imagem. Da indistinção entre as imagens e as coisas, adviria, pois, o apagamento da diferença entre ambas, como se o cinema arruinasse o trabalho remissivo próprio à literatura, na qual se via o aluno obrigado a ir das imagens extraídas das palavras às coisas ou, o que vem a dar no mesmo, levando o aluno ao ganho fácil do conforto e da estabilidade resultante do encontro com as próprias coisas: a suspensão da remissão faria com que aquilo que ainda não é no sentido forte - a imagem - fosse tida como o que já é - a coisa (Zanoni, 2015, p. 111).

Se Venâncio e Serrano viam uma das forças do cinema no fato de ele poder vir a contar em breve com "relevo e perfume" (Serrano; Venâncio Filho, 1931, p. 65), superando o defeito de estar a meio caminho de completar o trabalho total de presentificação das coisas, os pedagogos refratários ao cinema escolar localizavam sua tibieza. Até o vozerio militante pela expulsão do cinema da escola jamais questionou a associação entre lazer e educação, isto é, jamais torpedeou a tese de o cinema ser extremamente útil para a constituição de modelos lúdicos de internalização de certas expectativas de socialização. Nesse passo, rumamos para longe das recriminações que se projetavam sobre as capacidades educativas do rádio, por exemplo (Arquivo..., 1934). Ao não empregar senão o ouvido, o espectador, sobretudo em seus primeiros anos de vida, não podia senão fatigar-se com as transmissões radiofônicas. Assim, vemos que, mesmo entre os inimigos do cinema escolar, não se tratava de dizer que os filmes não capturariam a contento a atenção do espectador, quer dizer, a recusa do cinema escolar não tinha nenhum parentesco com os processos de desimersão descritos na análise do contato com o rádio ou com o brinquedo aborrecedor.

De um extremo ao outro, os termos do diagnóstico acerca dos poderes do cinema mantinham-se inalterados. Entre eles, a diferença era tão somente de valor. Se for correto que o cinema lúdico estava à altura 
da tarefa de suavizar a internalização de regras de socialização, não o era menos que tal modo de retenção do conteúdo exibido pelos filmes tinha como contrapartida o banimento do hábito escolar mais fundamental: o de pensar. Por isso, se antes a experiência lúdica imputada ao cinema era positivada pela internalização de certas expectativas escolares, agora era negativizada em decorrência da preguiça cognitiva que incentivava nos alunos, preguiça indissociável do poder de penetração osmótico da imagem em movimento:

Graças ao prazer dessa percepção e ao interesse afetivo que despertam os heróis, há o grande perigo de se cristalizar o hábito de contentar-se a mente com êsse vago sentimento de realidade [...], atitude de preguiça (Schmidt, 1958, p. 245).

A imagem em movimento, tendo o poder de fazer-se passar por coisa, dava lugar ao apagamento prematuro da própria imagem, apresentando-se como o contato direito com as coisas, como se o mal da imagem estivesse em ela radicar em uma falsa compreensão objetivista do mundo (que ela alegadamente apenas veicularia). Quando transladada para a economia argumentativa dos detratores do cinema escolar, a reconfortante certeza de a imagem visual ser mais forte do que qualquer outro meio de conhecimento tornava-se sinônimo de "facilidade" (Serrano; Venâncio Filho, 1931, p. 45). Por conta do seu automatismo, Neves transformava o cinema em réu:

O cinema não é mais do que a satisfação do espírito sem necessidade de cultura [...] a sucessão de imagens pelo mecanismo eléctrico em vez do mecanismo intelectual (Neves, 1946, p. 41).

Os males cognitivos das imagens em movimento já tinham sido constatados em eventos sociais que remontavam ao tempo em que a humanidade vivia sob o jugo nefasto da religião. Em certo sentido, o cinema dava continuidade às experiências religiosas experimentadas pelos crentes na relação com certas imagens sagradas, pois também ali ocorria a substituição da coisa pela imagem. Todos sabiam que o povo humilde venerava mais os santos pelas imagens do que por si mesmos (Gaspar, 1948). Patrono da política do espírito salazarista, António Ferro, valendo-se da mesma tradição, iria, dois anos depois de Gaspar, congratular a chegada do cinema:

O espectador do cinema é um ser passivo, mais desarmado do que o leitor ou do que o simples ouvinte. A própria atmosfera das sessões de cinema, com a sua treva indispensável, ajuda essa passividade, essa espécie de sono com os olhos abertos... Quase se poderia afirmar que não chega a ser necessário olhar para o écran porque são as próprias imagens dos filmes que se encarregam de entrar docemente, quase sem nos despertar, nos nossos olhos simplesmente abertos (Ferro, 1946, p. 44). 
Quando era a vez do teatro de surgir como termo de comparação, os impropérios dirigidos ao cinema não recaíam sobre a substituição das coisas pelas imagens. Nesse caso, $o$ ataque mirava na incapacidade de transformar as coisas em imagens. Se as personagens no écran eram objetos de identificação, as personagens na ribalta demandavam, em compensação, uma atividade cognitiva do espectador, sem a qual ele não seria capaz de abstrair a fisicalidade do teatro, e, portanto, não haveria algo como um mundo imaginário construído a partir dos objetos cênicos. Outra vez, vale a citação por extenso:

Quando a comparação se fazia com o teatro, o poder de penetração osmótico da imagem cinematográfica via-se convertido em impotência do espectador para a abstração da coisidade das coisas, de modo que aquilo que é no sentido forte - a coisa - recusava-se a ser transformado naquilo que ainda não é - a imagem. No caso do teatro, a imagem não era sinônimo de falta de objetividade. Era o resultado positivo de operações de abstração asseguradoras do trabalho imaginativo em curso. Mas, tanto do ponto de vista teatral quanto do literário, o fundamental na constatação do caráter defeituoso do trabalho cognitivo do ato de apreensão do cinema assentava-se na supressão do vaivém entre imagens e coisas, ora identificada na retenção gerada pela facilidade osmótica da imagem fílmica, ora associada à ausência de atividade de abstração das coisas, em prol de imagens, ambas responsabilizadas pelo transvio da consciência individual ativa (Zanoni, 2015, p. 114).

Portanto, o risco do cinema à cognição radicava em ele embotar o treino cognitivo do aluno-espectador, fosse ao expô-lo à imagem sem a coisa, fosse ao deixá-lo abandonado à coisa sem a imagem. De todo modo, não se pode deixar de vincar que essas autoridades reticentes diante da entrada do cinema na escola jamais diziam que a imagem em movimento levava o aluno a um estado passivo. Nos programas da Escola Nova, passivo era o mesmo que a imposição de conteúdos educativos contrários aos interesses dos alunos. De acordo com os jargões da época:

As modernas doutrinas pedagógicas deslocaram o centro de gravidade de toda a educação para a criança, cuja espontaneidade deve ser a única determinante da atividade escolar (Serrano; Venâncio Filho, 1931, p. 45).

Como acontecia com outras formas da experiência lúdica, a adesão ao cinema por parte dos alunos era tida como o efeito do encontro espontâneo entre o interesse dos alunos e as expectativas das autoridades escolares.

Contudo, poderíamos supor que o cinema talvez tivesse sido lido como empecilho à satisfação da exigência de um ensino estruturado de maneira "quasi individual" (Serrano; Venâncio Filho, 1931, p. 80). Basta pensar no seu caráter coletivo. Ora, acontece que o cinema jamais foi "[...] incompatível com os princípios cardeais da renovação cultural" 
(Serrano; Venâncio Filho, 1931, p. 46). Não podemos perder de vista que a dita modernização da escola não incentivava os caprichos dos alunos. Ainda que os teóricos da escola nova tenham alimentado o sonho do aparecimento de um "livro filme" (Serrano; Venâncio Filho, 1931, p. 154), livros cujas imagens se desenrolariam sobre a mesa de cada um dos alunos, nenhum deles tinha o direito de fazer o que queria, pois tinha que "querer o que faz" (Serrano; Venâncio Filho, 1931, p. 46). Chegado a esse ponto, fica fácil aperceber-se de que o cinema não vinha sendo criticado em termos de passividade, mas em termos de facilidade:

A verdadeira anatematização do cinema escolar estava alhures. Se a escolarização do cinema tinha em seu favor a participação e o interesse do aluno-espectador no processo de assimilação dos conteúdos escolares veiculados pelo cinema, a rotinização da facilidade do ato de recepção do cinema prejudicaria a complexidade da instrução, na medida em que apresentaria tudo já tão explicado e já tão digerido que o aluno-espectador não necessitaria da elaboração do cérebro para compreender os conteúdos internalizados. Em suma, não era a passividade, mas a facilidade da recepção do cinema que comandava o rechaço dos projetos de escolarização à volta dele (Zanoni, 2015, p. 116).

Acrescentaríamos: se a obediência inconsciente era o fator mais importante para a medição do sucesso das experiências lúdicas, pensar sem saber que se pensava não produzia nada senão atrasos e impedimentos para a correta instrução. Ponto importante: nenhum pedagogo posicionou-se contra o cinema per se, muito menos contra seus poderes educativos. O que se passava era que eles buscavam rebater o cabimento do cinema na escola por via da demonstração do desserviço do cinema para instrução do aluno-espectador. Prova disso é que foram as mesmas autoridades que lutaram pela saída do cinema da escola e pela criação de uma educação informal por meio do cinema. Tudo somado, eis o balanço final:

[...] se é verdade que a escola formal foi o berço da subsequente dissociação entre cinema educativo formal e cinema educativo informal, a partilha em questão não resultou da oposição ao cinema em geral, foi consequência da simultânea exibição das vantagens do cinema educativo apresentadas pelo polo favorável ao cinema escolar e das desvantagens do cinema instrutivo arrastada às barras do tribunal pelos inimigos do cinema escolar (Zanoni, 2015, p. 117).

Esses dispositivos internos da escola vocacionados ao lazer não foram senão, da missa, um terço. Olhando para fora dos muros da escola, as próprias autoridades escolares portuguesas iniciaram a organização de excursões, visitas a museus, passeios, para não mencionar o escotismo. Ora, as escolas brasileiras não tardaram a perseguir esse impulso de ampliação das horas de educação. A simetria de objetivos entre os diferentes países procede. No Brasil, incentivavam-se excur- 
sões “[...] feitas pelos alunos em grupo" (Serrano; Venâncio Filho, 1931, p. 116-117), sobretudo durante as férias. Mas também as viagens foram reinterpretadas como ocasião para o estímulo de hábitos vinculados aos "[...] prazeres sadios e econômicos" (Serrano; Venâncio Filho, 1931, p. 125), cujo cultivo marcaria, dizia-se, o presente e o futuro do alunado. Isso sem contar os museus, essas grandes casas de educação, onde os alunos tinham acesso a uma "[...] verdadeira miniatura da pátria" (Serrano; Venâncio Filho, 1931, p. 143), cujo aspecto diminuto não se incompatibilizava com o fato de o Museu Nacional não ter deixado "[...] nenhum grão de coisas esquecidas" (Serrano; Venâncio Filho, 1931, p. 145), sendo a amostra mais bem acabada da evocação viva do passado do país, e, por isso, parte das "[...] grandes escolas de educação popular" (Serrano; Venâncio Filho, 1931, p. 147). Tudo isso faz com que se torne mais ou menos evidente a assiduidade com que os pedagogos da escola nova confeccionaram dispositivos de educação para que eles se prolongassem para além do ambiente escolar formal. Trocando em miúdos:

\begin{abstract}
Assim, o que estava em jogo nessas diferentes experiências educativas de dilatação da jurisdição escolar era a colonização do ócio por vetores de força de cariz educativo interessados na conformação da conduta dos alunos. O otium deixaria de ser, assim, o tempo livre da jurisdição escolar. Se o lazer continuaria a ser definido em oposição à instrução, não se definia mais em oposição à educação. A passagem do ócio ao recreio livre marca o momento histórico em que a instituição escolar conquistou os territórios sociais ainda virgens de educação. Por um lado, se o sobredito recreio livre implicava redução das horas de instrução, por outro lado, maximizava o tempo dedicado à educação (Zanoni, 2015, p. 118).
\end{abstract}

\title{
Conclusão
}

Como vimos, erraríamos se acreditássemos que o cinema tenha se tornado instrutivo no contato com o ambiente escolar. Não foram os professores que ensinaram a experiência cinematográfica a assumir o lugar do mestre, mas sim os jovens colegas institucionais do cinema, desde a excursão, passando pelo esporte, até o escotismo, e isso porque foram eles os responsáveis por ensinar o cinema a não ser instrutivo, sem deixar de ser, no entanto, educativo.

Portanto, se o cinema educativo informal, aquele que anos depois seria conhecido como o de entretenimento, possui alguma dívida em relação ao cinema educativo formal, ela não se localiza na transmissão de conteúdos didáticos. Nesse sentido, o cinema escolar não frutificará. À contramão dos desejos de certos pedagogos otimistas frente ao futuro do cinema na escola, o cinema informal jamais foi eliminado pelo cinema educativo. Quando muito, o que restou para este foi uma mera "função supletiva" (Arquivo..., 1937, p. 16), já que ao cinema não era dado o direito de substituir o mestre. Por isso, um catálogo dessa natureza (Figura 1), catálogo circulado na década de 1940, em Portugal, sumiu do mapa escolar: 


\section{Figura 1 - Cinemateca da Embaixada do Canadá}

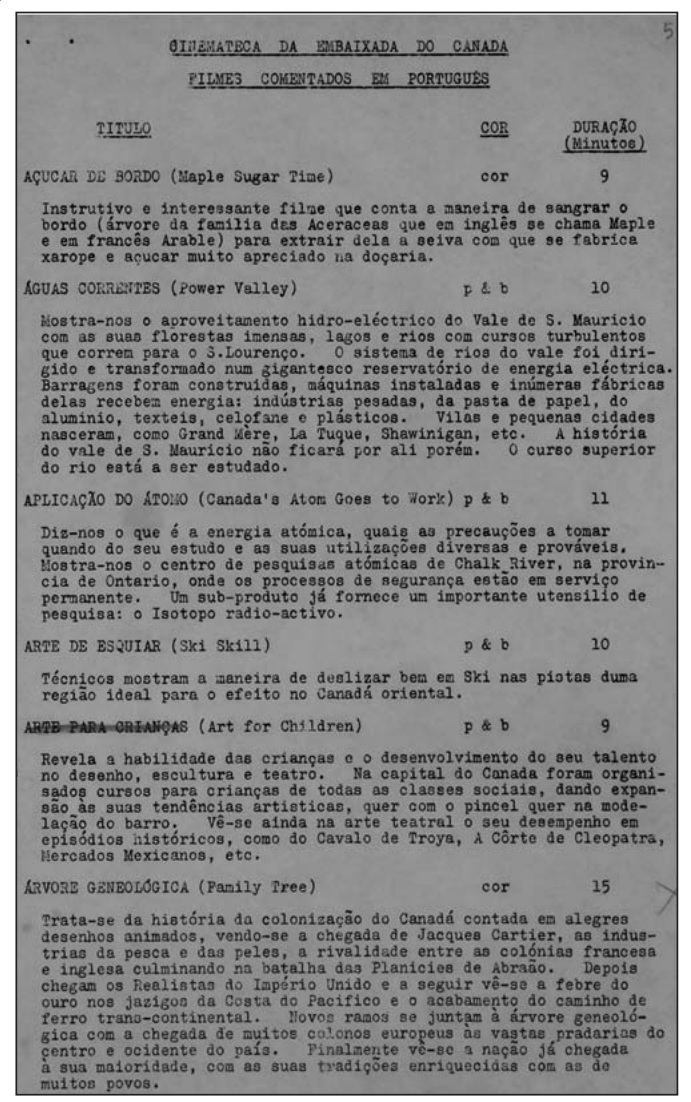

Fonte: Torre do Tombo (1940).

A maior herança que as escolas legaram para o cinema informal jaz na fusão entre disciplina e lazer. Daí a razão pela qual os Estados foram se valendo do cinema educativo informal à medida que o cinema perdia seus contornos escolares. Daí também o pouco caso dos representantes dos Estados diante dos argumentos daqueles que maldiziam o cinema em virtude dos seus danos à instrução, visto que a guinada estatal rumo à utilização do cinema deveu-se ao fato de o cinema intensificar a força das práticas de colonização do ócio (práticas destinadas à educação inconsciente e prazerosa). A arte da política tinha sua política das artes, uma política que, em certo sentido, minorou a importância da racionalidade forjada em torno dos imperativos de instrução escolar, muito embora tenha sido nessas conversações escolares que a dimensão inconsciente do cinema - entendida como instrumento de condução de condutas - tenha podido emergir.

Sob a perspectiva dos Estados, o cinema poderia e deveria ganhar centralidade como tecnologia de governo educativa, justamente em decorrência da facilidade da internalização de princípios de conduta. Vargas disparava: 
Elemento de cultura, influindo diretamente sobre o raciocínio e a imaginação, ele apura as qualidades de observação, aumenta os cabedais científicos e divulga o conhecimento das coisas, sem exigir o esforço e as reservas de erudição que o livro requer e os mestres, nas suas aulas, reclamam (Vargas, 1934, p. 2).

Se as autoridades escolanovista mostravam receios diante da integração do cinema na escola como instrumento educativo devido aos processos inconscientes que orientavam a formação cognitiva dos alunos, os Estados situavam o cinema entre os seus principais recursos de educação informal. O que acontecia era que havia uma diferença de alvo entre os agentes da escola e do Estado. Para aqueles, o aluno constituía o alvo. Para estes, a população em geral, nomeadamente o pequeno burguês e o iletrado, bem como todos os demais atores sociais que gozassem de baixo acesso à escolarização formal.

Recebido em 30 de março de 2015 Aprovado em 18 de novembro de 2016

\section{Referências}

ARAÚJO, Vicente de Paula. Salões, Circos e Cinema de São Paulo. São Paulo: Editora Retrospectiva, 1981.

ARQUIVO Gustavo Capanema. Arquivo Pessoal de Gustavo Capanema. Rio de Janeiro, 1934.

ARQUIVO Gustavo Capanema. Arquivo Pessoal de Gustavo Capanema. Rio de Janeiro, 1935.

ARQUIVO Gustavo Capanema. Arquivo Pessoal de Gustavo Capanema. Rio de Janeiro, 1937.

ARQUIVO Gustavo Capanema. Arquivo Pessoal de Gustavo Capanema. Rio de Janeiro, 1938.

ARQUIVO Gustavo Capanema. Arquivo Pessoal de Gustavo Capanema. Rio de Janeiro, 1940.

ASSEMBLEIA DA REPÚBLICA. Diários das Sessões da Assembleia Nacional: número 076. Lisboa, 10 fev. 1936.

ASSEMBLEIA DA REPÚBLICA. Diários das Sessões da Assembleia Nacional: número 12. Lisboa, 06 jan. 1939.

BOLETIM Cineclube do Porto. Cineclube de Portugal. Porto, 1953.

BOLETIM Cineclube do Porto. Cineclube de Portugal. Porto, 1955

DIDONET, Humberto. Você Sabe Apreciar Cinema? Porto Alegre: SESI, 1957.

DIETRICH, Ana Maria. Nazismo do Oiapoque ao Chuí: a distribuição dos grupos nazistas no Brasil dos anos 30. In: SILVA, Giselda Brito; GONCALVES, Leandro Pereira; PARADA, Mauricio Alvarez (Org.). Histórias da Política Autoritária: integralismos, nacional-sindicalismo, nazismo e fascismos. 1. ed. Recife: Editora da UFRPE, 2010. P. 17-20.

FERRO, António. Teatro e Cinema. Lisboa: Edições SNI, 1946.

FOUCAULT, Michel. Vigiar e Punir. Petrópolis: Vozes, 1987.

576 Educação \& Realidade, Porto Alegre, v. 42, n. 2, p. 557-577, abr./jun. 2017. 
FOULQUIÉ. Paul. As Escolas Novas. São Paulo: Companhia Editora Nacional, 1952.

GASPAR, José Maria. O Cinema e a Escola. Coimbra: Coimbra Editora, 1948.

GERTZ, René Ernaine. De Otto von Bismarck a Angela Merkel: do 'perigo alemão' ao 'neonazismo' no Brasil. História - questões e debates, Curitiba, v. 58, p. 89-112, jan./jun. 2013.

HEGEL, Georg Wilhelm Friedrich. Fenomenologia do Espírito. Petrópolis: Vozes, 1992.

HEGEL, Georg Wilhelm Friedrich. Princípios da Filosofia do Direito. São Paulo: Martins Fontes, 2009.

LIGA Portuguesa de Profilaxia Social. O Cinema e a Higiene Social. Porto, 1934. LOURENÇO FILHO, Manuel Bergström. A Pedagogia de Rui Barbosa. São Paulo: Edições Melhoramentos, 1956.

NEVES, J.A. da Cruz. Cinema e Cultura. Coimbra: Edições Estudo Coimbra, 1946.

NUNES, Leopoldo. A Alegria na Vida Escolar: e o poderoso exemplo da obra notável dum amigo do ensino popular. Lisboa: Arquivo Nacional da Torre do Tombo, 1943.

PENTEADO JUNIOR, Onofre de Arruda. Compendio de Psicologia: problemas de psicologia educacional. São Paulo: Edição do Autor, 1949.

SANTOS, Ediogenes Aragão. O Brasil de Olavo Bilac e Manoel Bonfim: a construção política de uma identidade nacional através do ensino. Pro-Posições, Campinas, v. 13, p. 21-35, 2002.

SCHMIDT, Maria Junqueira. Educar pela Recreação. Rio de Janeiro: Agira, 1958. SERRANO, Jonathas; VENÂNCIO FILHO, Francisco. Cinema e Educação. São Paulo: Editora Melhoramentos, 1931.

TORRE DO TOMBO. Cinemateca da Embaixada do Canadá. Lisboa: Arquivo Nacional da Torre do Tombo, 1940.

VARGAS, Getúlio. O Cinema Nacional: elementos de aproximação dos habitantes do país. Brasília, 1934. (Discurso). Disponível em: <http://www.biblioteca.presidencia.gov.br/presidencia/ex-presidentes/getulio-vargas/discursos/1934/04.pdf/view>. Acesso em: 20 out. 2014.

ZANONI, Fábio. A Censura sem Limites: as práticas de censura no cinema e seus ecos na contemporaneidade luso-brasileira (1930-1950). 2015. 516 f. Tese (Doutorado em Educação) - História da Educação, Universidade de Lisboa, Lisboa, 2015.

Fábio de Godoy Del Picchia Zanoni possui graduação (bacharelado e licenciatura) em Filosofia pela Universidade de São Paulo (2009) e mestrado em estética pela Universidade Nova de Lisboa (2012). Tem experiência na área de filosofia com especial interesse em Foucault e em outros trabalhos da mesma envergadura teórica aplicados à compreensão das relações entre estética e política.

E-mail: zanonifabio83@gmail.com 